\title{
Improving animal care
}

\author{
An interview with Rose Bartiss, RLATG, Animal Quality Control \\ Specialist, Mouse Production and Screening Services, \\ Trudeau Institute, Saranac Lake, NY
}

Rose Bartiss discusses her efforts to improve communication between different departments at the Trudeau Institute.

\begin{abstract}
How did you become interested in the lab animal science field?

Before I applied for a position at the Trudeau Institute, I had never thought about pursuing a career in lab animal science. However, I have always known that I wanted a career in which I could work closely with animals. I grew up around animals on a small farm, and I currently have a farm full of dairy goats and chickens. I also knew that I wanted a career in the sciences. Working at Trudeau Institute has allowed me to blend two things that I have hoped for in a job-being able to work with animals and in science.
\end{abstract}

\section{As the Animal Quality Control Specialist for the Trudeau Institute's Mouse Production and Screening Services, what is a typical workday like for you?}

I spend most of my time using a custom-made database system to track 118 breeding colonies of mice at the Institute. The Mouse Production and Screening Services group breeds mouse colonies that can be used by all of the labs at the Institute and also breeds mice by contract for individual lab use. I work with my supervisor to evaluate each mouse colony every week. We decide whether we need to replace older or non-productive breeders with new breeders. We also carefully monitor the breeding efficiencies of each breeder cage to make sure that we are producing enough mice for experimentation without producing too many extra mice.

You are quite involved in working to improve communication between different groups at the Trudeau Institute. Tell us about your involvement in this area.
Trudeau Institute is a small research facility located in a small town, away from the hustle and bustle of a larger city. Most people at the Institute know each other, and there is a lot of camaraderie between employees. I knew that the research technicians and labs would find the information I was learning about animal care to be useful. I also knew that any information the research technicians could share with me about what they were doing with the animals would help me to better care for the animals. I wanted to improve communication between the different departments for the benefit of the animals.

To improve communication at the Institute, I have used a couple of different tactics. I am the newsletter editor for the Northern Mountain Branch of the American Association for Laboratory Animal Science (AALAS). In each newsletter, I strive to include articles and information that benefit every level of lab animal scientist. I work hard to advertise local and national meetings to Institute staff. I have encouraged research technicians to become involved in AALAS and to pursue AALAS certifications at the Institute. Additionally, I have led a few in-house seminars about mouse breeding and nomenclature of strains. I work closely with the research technicians to provide topics for discussion at monthly "Tech Forums." These meetings were designed for lab research technicians, but I pushed to have the forums open to all staff. I thought that animal caretakers would particularly benefit from participation in the forums. I felt that the forum topics could enhance the education of the caretakers and that

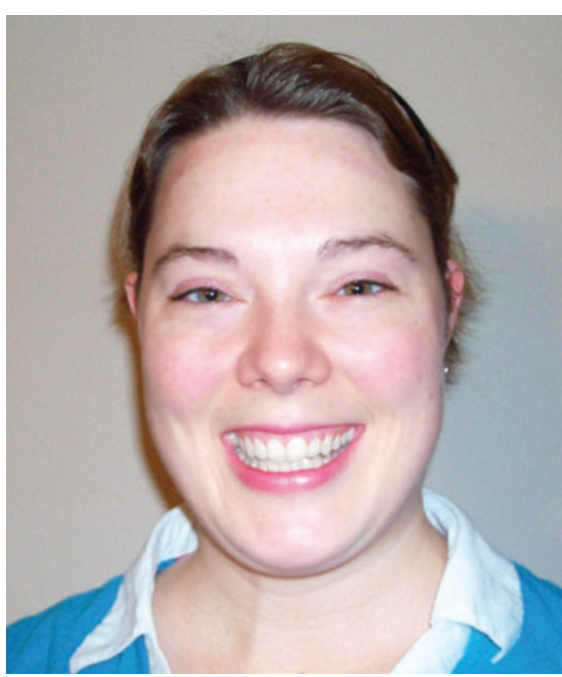

the caretakers' unique perspectives would be beneficial to the technicians.

\section{Do you have any recommendations for others interested in improving communication between different branches of their institution?}

Don't be discouraged by the mentality that the different branches in an animal research facility need to operate completely independently. We may work in different departments, but we are all working towards the same end goal: humane animal care to benefit the animals and scientific research. I have never felt that my role in a research project was less important simply because I didn't work in a lab like some of our staff members do.

I recommend using the resources available to you at your animal research facility and through AALAS. Most facilities already have forums for the discussion of scientific topics. These forums can easily be modified to give personnel an opportunity to discuss humane animal care. AALAS provides many resources, such as the AALAS Learning Library site, that are geared towards all forms of laboratory animal professionals. Local AALAS branches also have resources available for members and nonmembers.
Lab Animal welcomes nominations and contributions for Careers and Recruitment. Submissions should be sent via email to editors@labanimal.com. 